\title{
Del aula a la pantalla. Los valores sociales y ciudadanos y su representación en el cine*
}

\author{
Mónica Eliana García Gil**, Arturo Uscátegui Maldonado***, \\ Gloria Inés Ceballos Hurtado ${ }^{* * * *}$
}

Recibido: 12 de julio de 2011 Revisado: 10 de agosto de 2011 Aprobado: 24 de octubre de 2011

\section{Resumen}

Cuando los conocimientos, los ejemplos de la vida en familia y en sociedad, las pautas de comportamiento y los valores modelo comienzan a llegar desde lugares menos comunes y controlables, como los medios de comunicación y las industrias culturales, empieza a evidenciarse un desplazamiento frente al papel cumplido de manera tradicional por la escuela, la familia y las instituciones sociales y políticas, las cuales comienzan a ser insuficientes (en cuanto a sus alcances) para entender y asumir estos mensajes y sus referentes. Se generan, entonces, nuevas mediaciones frente a las cuales es cada vez más urgente dar razón. En este escrito se abordan algunas de las limitaciones, posibilidades y tensiones existentes cuando los valores (sociales y ciudadanos) se trasladan al relato cinematográfico.

* El presente artículo de reflexión, hace parte de los resultados investigativos de la Red Iberoamericana de Investigadores en Narrativas Audiovisuales (INAV).

** Magíster en Comunicación Televisiva (Universidad Pontificia Bolivariana), Estudios de Maestría en Comunicación (Pontificia Universidad Javeriana). Docente de Comunicación Visual en la Facultad de Comunicación Social para la Paz, de la Universidad Santo Tomás de Bogotá. Integrante de la Red Iberoamericana de Investigadores en Narrativas Audiovisuales (INAV). Investigadora principal del proyecto. Correo electrónico: monigarciagi@ yahoo.com

*** Especialista en Docencia Universitaria, candidato a Magíster en Filosofía Latinoamericana (Universidad Santo Tomás, Bogotá). Docente de Semiótica publicitaria en la Universidad Central, de Taller de Lengua I y de Comunicación Escrita en la Facultad de Comunicación Social para la Paz de la Universidad Santo Tomás de Bogotá. Co-investigador. Correo electrónico: arturousca@gmail.com

**** Doctora en Ciencias de la Información - sección Periodismo (Universidad Autónoma de Barcelona). Docente de Taller de Lengua Il y de Proyecto de Grado en el énfasis de Comunicación Organizacional, en la Facultad de Comunicación Social para la Paz, de la Universidad Santo Tomás de Bogotá. Co-investigadora. Correo electrónico: giceballos@hotmail.com 
Este artículo recoge reflexiones y aspectos derivados de la investigación. Recoge a su vez avances de la investigación en curso: Representación de valores sociales y ciudadanos en la producción fílmica colombiana (2003-2009). Un aporte para la formación de audiencias críticas, realizada por los autores, integrantes del grupo de investigación Comunicación - Paz / Conflicto, de la Facultad de Comunicación Social para la Paz, de la Universidad Santo Tomás, de Bogotá. Esta investigación cuenta con recursos del Fondo para el Desarrollo de la Investigación (FODEIN), de la misma universidad.

\section{Palabras clave}

educación audiovisual, cine, representación, ética, relato cinematográfico, valores. 


\title{
From the classroom to the screen. Social and citizens values and their representation in film
}

\author{
Mónica Eliana García Gil, Arturo Uscátegui Maldonado, \\ Gloria Inés Ceballos Hurtado
}

\begin{abstract}
When knowledge, life examples among the family and society, behavior rules and role models, and the values, start coming from uncommon and uncontrolled places, as the mass media and the cultural industries, a displacement starts being, pointing out to accomplish the role played by the family, social and political institutions which have started to show lack of knowledge to fulfill and assume those new messages and challenges. Then, it emerges new means that require urgent explanations. This written, point out the existence of limitations, possibilities and tensions that exist when social and citizen values are translated to the cinematography scene.
\end{abstract} Aprobado: 24 de octubre de 2011

\section{Keywords}

Audiovisual literacy, film, representation, ethics, filmic narratives, values. 


\section{INTRODUCCIÓN}

La investigación "Representación de valores sociales y ciudadanos en la producción fílmica colombiana (2003-2009). Un aporte para la formación de audiencias críticas", realizada por los autores de este escrito y que motiva las reflexiones acá consignadas, pareciera prefigurar, desde su mismo título, derroteros conceptuales que se mueven en el terreno de los lugares comunes y que, por tanto, sus objetivos no podrían ir más allá de los límites marcados por su propia descripción.

Tres factores sustentan esa restringida perspectiva: en primer lugar, el cine, como paradigma de las formas expresivas caracterizadas por lo social en todos sus procesos - producción, emisión y recepción-, que buscaba convertir al discurso cinematográfico en la antítesis de la sociedad capitalista y de la realidad existente, el contrario dialéctico del mercado y el colonialismo, tal como "el tercer cine" (Solanas y Getino, 1973) y el "cine imperfecto" (García Espinosa, 1982) planteaban ${ }^{1}$, y que por la consiguiente fuerza inercial de su esencia constitutiva encuentra sus temas en las dimensiones colectivas de la realidad humana. Aún si sus temáticas abordan las problemáticas internas, subjetivas, de un individuo, la emisión y recepción masivas de los filmes remiten tales obras intimistas a su dimensión social. Tal planteamiento se transforma en un modelo incapaz de dar respuesta a las problemáticas de la sociedad contemporánea.

En segundo lugar, el concepto de representación refuerza esa posible percepción del lugar común: pesa sobre el cine -y aún más

Véase León, Christian. (2005). El cine de la marginalidad. Realismo sucio y violencia urbana. Serie Magíster (Vol. 64). Ecuador: Universidad Andina Simón Bolivar. en el estado de desarrollo en que se encuentra el cine colombiano- con especial énfasis su carácter mostrativo. Es decir, el hecho de que sus imágenes reconstruyen supuestamente con fidelidad, bajo las metáforas del fiel reflejo y la lente neutra, una determinada realidad. En este sentido, no es suficiente asumir, continuando con las teorías realistas frente al cine (Bazin, Kracauer), el privilegio de la objetividad que otorga el cine a la realidad, en donde se pretende hacer desaparecer de este la mediación, para que emerjan las formas de lo real y lo cotidiano.

En tercer lugar, se manifiesta en esta propuesta investigativa el campo conceptual de la ética, y así mismo ronda el riesgo de la obviedad: tanto en el género del documental como en el de la ficción, a partir de la perspectiva analítica del primero y del relato de unas acciones realizadas por unos personajes del segundo, están sustentados por fuerza en unos determinados valores, poseen de suyo unas determinadas intencionalidades que les dan significado.

Entonces cabe la pregunta: ¿si el cine siempre representa valores sociales, en dónde puede radicar el aporte de esta investigación?

En una primera instancia este trabajo quiere tomar como punto de partida una evidencia reiteradamente formulada, pero a nuestro juicio aún no desarrollada de manera suficiente: las industrias culturales hoy ocupan el lugar protagónico que antaño tenían las prácticas e instituciones tradicionales -escuela, academia, iglesia, plaza pública, periodismo, agentes estatales- en la formación de las representaciones políticas e ideológicas (Sarlo, 1992, 1994; Schmucler y Mata, 1992). Así entonces, es la industria comunicacional, informativa y audiovisual la que llega a instaurar y a reorganizar los gran- 
des relatos, que hasta hace poco se creyeran desaparecidos. El poder de la visibilidad y de la audibilidad entra ahora a configurar modelos, opiniones y horizontes de sentido que llegan a ser aceptados socialmente.

La insuficiencia aludida en líneas anteriores apunta, por lo pronto, en dos direcciones y señala por tanto tres posibles desarrollos investigativos: el primero consiste en la superación de la perspectiva que adjudica a las industrias culturales un efecto de banalización y espectacularización de los contenidos que llegan a ellas (no se trata de cuestionar los ya desusados argumentos de la alienación y la manipulación e incluso habrá que matizar el planteamiento de la traslación de las lógicas del espectáculo al campo de la formación política). De lo que se trata es de explorar los efectos particulares, las modalidades específicas y los nuevos usos y significaciones que posiblemente emergen cuando los dispositivos representacionales de los valores cambian y asumen las lógicas de la enunciación cinematográfica, por ejemplo.

El segundo desarrollo investigativo roza los planteamientos de la estética de la recepción (Jauss, Benjamin, Eco) y se pregunta por el cambio de estatuto del sujeto que construye esas representaciones de valores sociales y ciudadanos a partir de los flujos comunicativos en los que participa. Esta investigación ha indagado por el sentido de esa transformación: ¿qué es lo que cambia en el proceso de apropiación de un valor cuando interviene como instancia mediadora la representación cinematográfica?, ¿existen unas disposiciones comunicativas $\mathrm{y}$ unas afecciones ${ }^{2}$ particulares en el espec-

2 Ya Aristóteles en la Poética hablaba de la catarsis como una función de la tragedia griega que tenía un efecto terapéutico en el especta- tador de la ficción cinematográfica? $\mathrm{O}$ en otras palabras, ¿qué va del alumno, del feligrés, del participante en la manifestación política que escucha una arenga, del lector de noticias, al espectador de cine?

Consideramos entonces que cuando el espectador está frente a la pantalla se convierte en parte fundamental del filme, pues si bien es cierto que el realizador pone en escena el tema y el desarrollo del mismo, solo cuando hay un espectador frente a este, el mensaje es recibido e interpretado y así tiene lugar el encuentro de las dos subjetividades. La interpretación, por tanto, saca al espectador de la razón y lo lleva a interiorizar contenidos visuales y sonoros que le permiten realizar una hermenéutica. En términos de Ricoeur (2003), “la interpretación es el trabajo de pensar, el cual consiste en descifrar el sentido escondido en el sentido aparente, a explicar los niveles de significación integrados a la significación literal". Puede decirse que este es el momento en que el filme realmente existe.

El tercer abordaje investigativo se inscribe de lleno en el campo de la ética y se pregunta por el contenido, la historicidad o estructura de los valores, pero en una perspectiva bien particular: ¿son los valores mismos representaciones?, ¿existen otras formas de apropiación, comprensión o construcción de los valores en las que no intervengan procesos representacionales? El planteamiento es de índole fuertemente comunicacional ${ }^{3}$

dor, incluso de purificación. Podía lograrse por la puesta en escena de la obra o por el argumento de esta. Desde la teoría de los usos y gratificaciones, la teoría psicoanalítica en relación con la teoría del filme, los estudios culturales y la etnografía de las audiencias, se han hecho estudios con aplicaciones más recientes al cine y la televisión (ver Morley, 1996).

3 McLuhan $(1967,1996)$ y Thompson (1998) han hablado de cómo los contenidos de los mensajes se ven afectados por el medio que los transmite. 
y postula que el contenido referencial de los intercambios informativos se afecta, se modifica en atención a los soportes de esos intercambios y a las competencias específicas que ponen en juego los participantes en ellos. En tal sentido, esta investigación se ha preguntado por la intervención de la mediación cinematográfica en la representación de los valores en tres niveles o momentos: cuáles son las representaciones que proponen los filmes -contenido de la representación-, cómo son cinematográficamente esas representaciones -forma de la representación-, cómo se constituyen unas nuevas representaciones de valores o se modifican las ya existentes o se articulan a las representaciones de otras fuentes mediadoras de los receptores cinematográficos -efectos del proceso de representación-.

La segunda dirección de este trabajo, anunciada antes, apunta a establecer un espacio de relaciones entre los campos de la ética y la estética a partir del concepto de la representación. Tomamos distancia de las posturas moralizantes que determinan una dimensión ética de la estética desde los supuestos efectos socializadores del cine. Si bien no se puede negar que en otros momentos las industrias culturales, como el periodismo en la formación política o la telenovela en la educación citadina, han brindado marcos de comprensión de nuevas realidades a los nacientes procesos de la democracia o de la urbanización de las poblaciones latinoamericanas (Martín-Barbero y Muñoz, 1992; Martín-Barbero y Rey, 1999), tales efectos sociales han sido suficientemente documentados. No interesa tanto acá concebir al cine como una herramienta de divulgación, sensibilización o conocimiento frente a unos determinados valores, sino explorar, de un lado, desde categorías de la estética, la posibilidad de formular nuevas vías de comprensión del cine en tanto forma expresiva desde su representación de valores $\mathrm{y}$, de otro, someter a análisis los cambios del contenido, estructura y sentido de los valores sociales y ciudadanos cuando son objeto de la representación cinematográfica.

Preguntarse por la construcción cinematográfica de los valores sociales implica cuestionarse frente a la mediación del cine y cómo tiene lugar allí la representación de estos, entendiendo acá la representación en una doble perspectiva: de cara a la ética, en cuanto a que los contenidos, su tratamiento y el sentido de los valores se ven afectados por la mediación cinematográfica (lenguaje, relato). Es decir, los valores puestos en pantalla no aparecen en estado puro, son necesariamente una representación y, por tanto, su contenido cambia, diferente a las mediaciones que suponen lo escrito, la oralidad, las clases magistrales o los discursos políticos. Acercarse a la representación desde la perspectiva de la estética significa analizar los dispositivos que desde la "forma" cine dan lugar a unos valores, cómo se construye el enunciado "valores", a partir de qué estrategias retóricas, propias del lenguaje cinematográfico. Desde esta perspectiva se abre una posibilidad particular, poco explorada, que requiere indagar las tensiones que tienen lugar entre la ética y la estética, para llegar a establecer lo propio de esta construcción.

El filósofo francés Jacques Rancière (2005) ha afirmado que los cambios frente a las imágenes y frente a la obra de arte se relacionan también con los cambios en el régimen de percepción frente a la obra artística, lo que lleva a que la comprensión frente a lo que se denomina arte también cambie. Para 
él, lo que otros teóricos han denominado modernidad artística es llamado régimen estético del arte, que va a imponer una idea distinta del pensamiento que interviene en el arte.

En el régimen representativo, el trabajo del arte está pensado a partir del modelo de la forma activa que se impone a la materia inerte para someterla a los fines de la representación. En el régimen estético, esa idea de la imposición voluntaria de una forma a una materia se ve recusada. El poder de la obra se identificará en adelante con una identidad de contrarios: identidad entre lo activo y lo pasivo, pensamiento y no pensamiento, lo intencional y lo inintencional" (p. 140).

Para Rancière, el arte no es una sustancia dada, sino que corresponde a una idea del arte dentro de regímenes específicos. Lo mismo sucede con el cine, va a estar atravesado, marcado por diferentes regímenes. Así como hay una idea del arte asociada a un régimen estético, hay que reconocer también un régimen ético y uno poético.

El régimen estético se separa totalmente de las funciones del objeto. La separación de la experiencia supone la suspensión de las facultades que están en juego en la vida cotidiana para dar paso a la construcción de una esfera autónoma de la experiencia. A partir del siglo XVII, cuando surge la estética como concepto, lo poético se pone al servicio de la sensibilidad.

El régimen representativo clásico puede asociarse con un régimen ético del arte, orientado hacia un arte útil. La imagen no es en tanto representación sino en tanto su funcionalidad. Acá no existe diferencia entre los objetos de la vida cotidiana y los objetos artísticos; predomina la función que cumple, no lo que representa.

En el régimen poético la pregunta es por la dimensión formal del arte, por las normas que la constituyen, los procesos de conformación y cómo está compuesta la imagen o la obra de arte, según unos parámetros preestablecidos. No hay separación total del régimen estético.

Rancière considera que el cine, por sus particularidades y su dispositivo material, no puede inscribirse en el régimen estético, en la medida en que no se debe asumir solamente desde su dimensión de forma pura, o en palabras de Deleuze (1986) como expresión óptica y sonora pura en donde se rompe la organicidad, para dar paso a una materia inmaterial ${ }^{4}$.

En términos más concretos, a través de esta investigación, planteamos invertir la fórmula: indagar la dimensión estética de la ética a partir de una problematización de sus relaciones. Este planteamiento también nos invita a distanciarnos de comprender ese campo de relaciones como la posibilidad de adjudicarles a las manifestaciones virtuosas del obrar unas ciertas características trascendentes, observables a través de la emoción.

Si aceptamos que cada arte busca dar cuenta de sus propios procedimientos técnicos, problematizar la relación entre ética y estética en el cine de ficción pasa por preguntarse por la "forma" cine y por la dimensión técnica del cine. Así las cosas, la reflexión en torno a la ética y el cine está ligada a la

4 Véanse los planteamientos de Jean Epstein en "Buenos días cine", citados por Rancière (2005). 
forma específica de la imagen fotográfica en movimiento.

Esta discusión tiene sus orígenes en el Renacimiento, cuando con el surgimiento de la perspectiva, "la pintura se encontró dividida entre dos aspiraciones: una propiamente estética -la expresión de realidades espirituales donde el modelo queda trascendido por el simbolismo de las formas- $y$ otra que no es más que un deseo totalmente psicológico de reemplazar el mundo exterior por su doble. Esta última tendencia devoró poco a poco a las artes plásticas" (Bazin, 1990: 25) incluyendo al cine de carácter figurativo.

El conflicto se da a partir de la oposición ente el realismo estético, que busca expresar la significación concreta del mundo y tiene como inspiración el poder expresivo de la imagen y el realismo psicológico que se complace con el parecido, la ilusión, la copia de las formas (Bazin, 1990). En este sentido, el primero no se enfoca solamente en un proceso de representación de lo real, sino que va más allá trayendo nuevas experiencias visuales, haciendo evidente lo que antes no lo era.

Podemos afirmar, junto con Bazin (1990), que la fotografía ha librado a las artes plásticas de su obsesión por la semejanza, en tanto que, junto con el cine, busca satisfacer de manera definitiva y en su esencia misma la obsesión del realismo. Por el contrario, la pintura se esforzaba por crear la ilusión, la cual era suficiente para este momento en el arte (p. 26).

De otro lado, si consideramos la estética como la manifestación externa de un sentimiento, mientras que a la ética como el fundamento razonado y racional de los sentimientos, la ética se va a manifestar a través de la estética (Ripoll, 2004). En esta línea, entonces, el propósito de la ética es provocar la reflexión de las acciones del ser, en relación con los valores. Se da en la libertad consciente y personal, frente a la relación con el otro, en su contexto histórico social y cultural.

Enmarcando la discusión en terrenos de la comunicación y complementando lo anterior, Ara (2006) afirma que

la lectura visual en procura de un contenido que va más allá de la estética tradicional es una extensión de los procesos de comunicación. Los cánones griegos de la estética pretendían normar los aspectos externos de sus obras, caracterizadas por su profundidad y contenido. El elogio de la estética a lo largo de la historia la ha apartado de esa vinculación con el contenido. Asumir y retomar nuevamente esa vinculación supone entender no solo la estética como texto y contenido; sino aceptar que la ética, reflejada en el contenido, forma parte de los criterios estéticos.

Trasladada a distintos géneros y soportes de las narraciones contemporáneas, la relación entre ética y estética no debe verse como un añadido, algo que aparece forzado, sino más bien reconocer que la ética es constitutiva de poéticas y de distintos géneros de la historia del arte, en la medida en que estos plantean argumentos e historias que involucran problemas éticos y de valores. Por tanto, la relación entre las narraciones (teatro, cine, televisión) y la ética no debe ser vista como un plus, como un agregado que deben tener las narrativas o como un apéndice que es necesario incluir (Mazziotti, 2003:47-48).

Cabe destacar que, como bien apunta Mazziotti (2003), cada género, desde las for- 
malizaciones que instalan las distintas poéticas, tiene un cometido moral y guarda relación con valores y conductas de épocas determinadas. No puede pensarse una ficción que no toque alguna instancia ética. Desde el solo hecho de mostrar, de enfocar una situación, hasta la toma de partido de manera directa y frontal, las narraciones teatrales, cinematográficas y televisivas se vinculan con valores y postulados de la cultura social.

Más allá de aquellos discursos audiovisuales que pueden privilegiar las formas de espectáculo que, siguiendo a Rincón (2003), nos han construido un gusto contrahecho, banal, fragmentario, sicótico, de vinculación pero sin sentido, la investigación que genera esta reflexión se propone, además de analizar, contextualizar, conceptualizar $\mathrm{y}$ formular una propuesta metodológica útil para la comprensión del relato fílmico, formar para la lectura crítica de productos cinematográficos. Esta lectura crítica permitirá revelar la propuesta estética y narrativa que estos contienen y así posibilitar una mayor sensibilidad que permita vincular estos mensajes y sus propuestas expresivas con el contexto colombiano en el cual están inmersas y desde donde tiene lugar el proceso de recepción.

Esto nos lleva hacia una mirada de la ética y la estética desde una postura relacional, más que excluyente, con el fin no solo de vincular el cine con unos contextos (social, histórico, cultural), sino también, de identificar los componentes expresivos del código cinematográfico y la mediación de estos en la construcción de los valores sociales y ciudadanos, a partir de reconocer la especificidad representacional del cine.

\section{Por una alfabetidad AUdiOvisual. LA NECESIDAD DE UNA PEDAGOGÍA DE LA IMAGEN}

Desde las instituciones educativas, resulta imperativo avanzar en la definición de los mecanismos que apunten a la formación de personas críticas, conscientes y responsables frente a los mensajes de los medios de comunicación, en este caso audiovisuales. Se requieren personas que sean capaces de dar cuenta de los procesos de recepción y evidenciar la mediación de estos medios, con el fin de lograr mayores niveles de comprensión entre los públicos, a partir del reconocimiento de los elementos que conforman el lenguaje audiovisual, las representaciones que allí tienen lugar, la construcción del relato cinematográfico y las características de los mensajes del cine en una época y en unas producciones determinadas.

En este contexto, el cine no puede considerarse solo como espacio para el entretenimiento, sino también de interacción, de modelos de identidad, es decir, de lugares desde los cuales se aprende de uno mismo, del "otro" y de los "otros" (Quiroz, 2003: 17). Para lograr lo anterior, hoy más que nunca es necesario pensar y asumir la educación y los procesos formativos por fuera del salón de clase. Esto lleva a pensar la educación desde otro punto de vista, menos centralizado en la institucionalidad del acto educativo por vías tradicionales, sino más en relación con las experiencias, en particular con las generadas por los medios de comunicación y los productos culturales. Esto significa apropiar los contenidos del cine para, a través de ellos, posibilitar encuentros que deriven en aprendizajes, diálogos, toma de conciencia y reconocimiento de la realidad y el entorno. De esta manera, se 
ponen en juego visiones de mundo, sensibilidades y apreciaciones en relación con los mensajes derivados de producciones mediáticas y productos culturales como el cine, que pueden ser incorporados por las audiencias en sus procesos de conocimiento y reflexión en la vida cotidiana.

El ámbito educativo no se ha escapado al auge de las imágenes en movimiento, de allí que surja preocupación e interés frente al uso, los impactos y las posibilidades narrativas, pedagógicas, investigativas y de lectura del cine (también de la televisión y el video). Uno de los aspectos por reconocer es la necesidad de una formación en cuanto a competencias de lectura audiovisual o de alfabetidad audiovisual (Dondis, 1990), entendida esta como la capacidad para leer, construir y comprender signos, símbolos y mensajes visuales a partir del reconocimiento de su estructura formal.

Actualmente se evidencian profundas transformaciones en cuanto a los modos de leer, que dejan sin piso la identificación de la lectura solamente con el libro (impreso) y no con la pluralidad y heterogeneidad de textos, relatos y escrituras (orales, visuales, musicales, audiovisuales) que hoy circulan (Martín-Barbero y Rey, 1999: 43), lo cual obliga a las instituciones educativas (básica, secundaria y profesional) a reconfigurar sus propuestas de enseñanza-aprendizaje frente a distintos lenguajes, escrituras y formas de acceder al conocimiento.

En este sentido, alcanzar una alfabetidad audiovisual resulta indispensable para leer e interpretar las imágenes y los mensajes del cine; así mismo, para la creación de productos audiovisuales acordes con el lengua- je, la estética y las lógicas de producción que estos suponen. Un uso pedagógico creativo y crítico de los medios de comunicación puede aportar la posibilidad de aprender de los medios en lugar de aprender por los medios; apropiarse críticamente de sus contenidos y descifrar los cambios (Quiroz, 2003: 70).

Se debe propender más por una "pedagogía de la imagen" que por la "pedagogía por la imagen", que privilegia la imagen exclusivamente como apoyo a aquello que se quiere decir o comunicar. Para Quiroz (2003), en la pedagogía de la imagen se destacan la imagen y su soporte tecnológico como expresiones de "algo": la imagen como sentido y por lo que comunica. En esa línea, para el usuario sujeto de la pedagogía, se trata de tener acceso a la imagen como un ejercicio de sensibilización, al mismo tiempo que se descubren las estructuras lógicas que gobiernan las representaciones de las cosas y las intencionalidades comunicativas de sus autores.

Lo anterior nos lleva a preguntarnos por el tipo de diálogo que posibilitan los mensajes del cine, tanto entre ellos mismos como con las personas del entorno cercano (en cuanto a la socialización y la sociabilidad) y asumir de manera integral el estudio del cine, sin escindir imagen y contenido, forma y mensaje; el uno no contiene al otro, uno de ellos no solo expresa al otro, uno de ellos no es menos importante que aquello que presuntamente contiene, sino que, de acuerdo con Bordwell y Thompson (1995), son componentes de una estructura global percibida que establecen relaciones entre sí.

\section{REFERENCIAS}


Ara, H. (2006). Estética de la ética. Revista Interacción, 45. Recuperado el 12 de junio de 2009 desde http://interaccion. cedal.org.co/documentacion.htm? $\mathrm{x}=201$ $53783 \& \mathrm{cmd} \% 5 \mathrm{~B} 126 \% 5 \mathrm{D}=\mathrm{c}-1-^{\prime} 45^{\prime}$

Bazin, A. (1990). ¿Qué es el cine?. Barcelona: Rialp.

Bordwell, D. y Thompson, K. (1995). El arte cinematográfico. Barcelona: Paidós.

Deleuze, G. (1986). La imagen - tiempo. Estudios sobre cine II. Barcelona: Paidós.

Dondis, D.A. (1990). La sintaxis de la imagen. Barcelona: Gustavo Gili.

Kracauer, S. (1996). Teoría del cine, la redención de la realidad física. Barcelona: Paidós.

León, C. (2005). El cine de la marginalidad. Realismo sucio y violencia urbana. Serie Magíster Vol. 64. Ecuador: Universidad Andina Simón Bolívar.

McLuhan, M. (1996). Comprender los medios de comunicación. Las extensiones del ser humano. Barcelona: Paidós.

Martín-Barbero, J. y Muñoz, S. (1992). Televisión y Melodrama. Bogotá: Tercer Mundo.

Martín-Barbero, J. y Rey, G. (1999). Los ejercicios del ver. Barcelona: Gedisa.

Mazziotti, N. (2003). Sobre las relaciones entre ética y géneros de ficción audiovisual. Signo y Pensamiento, XXII (42) 4755. Bogotá: Facultad de Comunicación Social - Pontificia Universidad Javeriana.

Morley, D. (1996). Televisión, audiencias y estudios culturales. Buenos Aires: Amo- rrortu.

Quiroz, M.T. (2003). Aprendizaje y comunicación en el siglo XXI. Bogotá: Norma.

Rancière, J. (2005). La fábula cinematográfica. Reflexiones sobre la ficción en el cine. Barcelona: Paidós.

Ricoeur, P. (1996). Sí mismo como otro. México, Madrid: Editorial Siglo XXI.

Ricoeur, P. (2003). El conflicto de las interpretaciones: Ensayos de hermeneútica. Buenos Aires: Fondo de Cultura Económica.

Rincón, O. (2005). Estéticas de los viejos medios. En Tecnocultura y comunicación (pp. 119-134). Bogotá: Cátedra UNESCO de Comunicación Social - Pontificia Universidad Javeriana.

Ripoll, L. (2004). Wagner, ética y estética. Recuperado el 12 de junio de 2009 desde http://archivowagner.info/20040106. html

Sarlo, B. (1992). Estética y política: La escena massmediática. En: Schmucler, H. y Mata, M.C. (Coords.) Política y comunicación. ¿Hay un lugar para la política en la cultura mediática? Córdoba, Argentina: Universidad Nacional de Córdoba.

Sarlo, B. (1994). Escenas de la vida posmoderna. Buenos Aires: Ariel.

Schmucler, H. y Mata, M.C. (coords.). (1992). Política y comunicación. ¿Hay un lugar para la politica en la cultura mediática? Córdoba, Argentina: Universidad Nacional de Córdoba.

Thompson, J.B. (1998). Los media y la modernidad. Barcelona: Paidós. 